\title{
Nursing Performance Regarding Immediate Management of Carotid Artery Rupture
}

Amany Sayed Hasaneen ${ }^{1}$, Olfat Abd El-Ghany Shawer ${ }^{2}$, Mona Aly Mohammed ${ }^{3}$.

Specialist nursing, Faculty of Nursing, South Egypt Cancer Institute, Assiut University, Assiut, Egypt.

Assistant Professor of Critical \& Emergency Care Nursing, Faculty of Nursing, Assiut University, Assiut, Egypt.

Assistant Professor of Critical \& Emergency Care Nursing, Faculty of Nursing, Assiut University, Assiut, Egypt.

\begin{abstract}
Background: Patients with head and neck cancer are in danger of creating carotid artery rupture that may cause lifethreatening problems and death Aim: to assess the nursing performance regarding immediate management of carotid artery rupture. Study design: A descriptive research design was utilized in this study. Setting: The study was conducted in the critical care unit at south Egypt cancer institute at Assiut University hospital. Sample: A convenience sample of all available nurses (forty nurses) Tools: two tools were used for data collection, Nurses' knowledge assessment and observational checklist. Results: The majority of studied nurses $\quad(80 \%)$ were having an unsatisfactory level of knowledge regarding carotid artery rupture. Conclusion: Nurses` knowledge regarding carotid artery rupture and practice regarding immediate care of carotid artery rupture in critical care unit at south Egypt cancer institute at Assiut University hospital is unsatisfactory and have an inadequate level of knowledge and practice. Recommendation: Nurses need for in-service training programs to improve their knowledge and practice regarding the management of carotid artery rupture.
\end{abstract}

\section{Keywords: Carotid Artery Rupture, Head \& Neck Cancer, Nursing Performance, Immediate Management.}

\section{Introduction}

Nurses spend more time with patients than do any other health care providers and patient outcomes are affected by nursing care quality. Thus, improvements in patient safety can be achieved by improving the nurse's performance. Nursing performance, including cognitive, physical, and organizational factors that affect such performance, focusing on research studies that reported original data from nurse participants, the nurse's work system often does not accommodate human limits and capabilities and that nurses work under cognitive, perceptual, and physical overloads. (De Lucia et al., 2009)

Massive hemorrhages occur in $6 \%-10 \%$ of patients with advanced cancer. Acute carotid blowout syndrome is the most severe massive hemorrhagic complication in head and neck cancer patients. Rupture of the carotid arteries, which provide blood supply to the head and neck, results in huge discharge prompting demise inside only minutes in $33 \%$ of cases. The individuals who endure are regularly left debilitated. Patients with head and neck malignancy, who are over 50years of age with unreasonable weight reduction and diminished hemoglobin, have a more serious danger of carotid vein harm prompting burst, as have those with existing healthful inadequacies, cardiovascular or renal illness, or endocrine issue. Avoidance incorporates enhancing the wholesome status, averting contamination and blockage, advancing mending and utilizing safe suctioning (Hofmann, et al., 2012)

Risk factors for carotid blowout syndrome in patients with head-and-neck malignant growths incorporate pharyngocutaneous fistula, wound infection, presentation to salivation, radiation treatment, and radical resection and depriving of the carotid sheath, flap necrosis with the carotid introduction, and repetitive tumor. In patients with head-and-neck malignancies, past illumination builds their danger of CBS and most generally, patients have a background marked by squamous cell disease as the carotid course gets its blood supply by means of the vasa vacuum, forms that trade off this supply may prompt debilitating of the vessel divider, ensuing dilatation, and conceivable burst. Other than radiation and depriving of the carotid supply route amid the medical procedure, hazard factors incorporate mucocutaneous fistula, exposure of the carotid artery to air from skin breakdown, and subsequent drying. (Shah et al., 2011)

Carotid blowout syndrome has been ordered by as "threatened," where the carotid conduit is presented to the oral hole or outer condition by means of skin breakdown or by direct tumor intrusion; "impending," in which sentinel drains have happened yet have been controlled by conservative management; or "acute," where there is active bleeding (wan, et al., 2015)

Carotid artery rupture is a possibly deadly condition that requires quick activity with respect to the nurse

Vol , (7) No , (17) June, 2019 
who is present and available. The size of the rupture and the prognosis for the individual patient determine whether or not active resuscitation is undertaken. Calm, careful explanations should be given to patients and relatives and the decision regarding resuscitation should be recorded in the patient's notes. In the case of unanticipated conditions where a crack happens, a functioning nursing care plan ought to be founded and care taken to keep relatives all around educated. The patient's airway ought to be kept clear using suctioning, inflation of tracheostomy tube cuff and correct positioning. Sedative medication and palliative care may accordingly be vital. Support and help given to all who witness or are associated with the care of these patients are necessary (Frawley \& Begley, 2013).

\section{Significance of the study}

Carotid blow out syndrome patient need distinct nursing care to improve the patient outcome and prevent complication, so this study will assess nursing performance regarding immediate management of carotid artery rupture, the reported incidence of head and neck cancer patient in south Egypt cancer institute at 2015/2016 was about 547 patients. (South Egypt cancer institute statistical record, 2017)

\section{Aim of the study}

Assess the nursing performance regarding the immediate management of carotid artery rupture.

\section{Research question}

What are the nursing performances regarding the immediate management of carotid artery rupture?

\section{Materials \& Methods \\ Research design}

A descriptive research design was utilized in this study.

Setting: The study was carried out at oncology intensive care unit at south Egypt cancer institute

\section{Sample}

A convenience sample of all available nurses who provide direct patient care, participating in the study, and had at least one year experience.

The sample size was (40) nursing staff .It include technical nurses (21), secondary school (10) and baccalaureate degree (9) at south Egypt cancer institute.

Tools of data collection: The researchers utilized two tools in this study:

Tool (I); Nurses' knowledge Assessment: -It's divided into two parts:-

Part (1): Demographic data of the studied nurses: It was utilized to assess demographic characteristics as (code, age, sex, marital status, qualification and years of experience, etc......).

Part (2): Structured knowledge questionnaire sheet:

It was developing to assess nurse's knowledge as \{Definition, singes \& symptoms, risk factor, types, complication, and nursing role $\}$.

\section{Scoring system}

For multiple choice questions, each right answer was given (one) score and each incorrect was given (zero) score.

This includes 32 questions; Scores assigned to each item are between 0 and 1 point as follows; (incorrect and correct).

According to the range of total scores lie between ( 0 - 32). Nurse's knowledge was classified as :

Satisfactory knowledge $\geq 70 \%$, Unsatisfactory knowledge $\leq 70 \%$ (Bond,2017)

Tool (2); Observational checklist: (Riesenberg et al., 2014)

This tool was developed by the researcher based on current national and universal literature based on a related critical nursing technique to assess nursing practices regarding carotid artery rupture.

An observation checklist was developed to assess the practical aspects of the basic nurses' procedure about preparations of immediate care of the patient with (carotid artery rupture) as prevent infection, maintain an open airway, suction, dressing change, continuous I.V infusion, oxygen therapy, and blood transfusions.

\section{Scoring system}

By using a Likert scale, scores assigned to each item are between ( 0 and 3 ) points as follows; (not done= 0 , inapplicable $=1$, done in correct $=2$ and done correct $=3$ )

The total score was 293 degrees.

According to the range of total scores considering poor practice less than $70 \%$ from the range of total score. Patient's practice level was classified as: the total score was $70 \%$ and more $=$ good practice

\section{Ethical approval}

An official authorization to conduct the study was obtained by the researcher from the dean of the South Egypt Cancer Institute. Oral consent for voluntary participation was obtained from each nurse, and the nature and purpose of the study were described. The researcher emphasized that participation is voluntary. Confidentiality and anonymity of the subjects were assured through coding of all data.

\section{Method}

Official approval was obtained from the responsible authorities at the previously mentioned research setting after clarification of the purpose and nature of the study. 


\section{Methods of data collection}

- An individual interview was used to collect data, the time needed to complete the tool was 15 minutes (nurse knowledge assessment questionnaire)

Every nurse was interviewed at break time to collect data. Data collection was carried out from "January 2018 until May 2018".

\section{- (Observational checklist)}

Every nurse was observed to collect data of observational checklist, for nurses carried out during the morning and afternoon shift.

\section{The technique for data collection}

The study was conducted throughout three main phases which include: preparatory, implementation and evaluation phase.

1-preparatory phase

This phase involved

\section{Ethical consideration}

- The research proposal was approved from ethical committee in the faculty of nursing. There was no risk for study subject during application of the research. The study was following common ethical principles in clinical research. Informed consent was obtained from patients or guidance that is willing to participate in the study after explaining the nature and purpose of the study. Confidentiality and anonymity were assured. Patients have the right to refuse to participate and or withdraw from the study without any rationale at any time. Patient privacy was considered during the collection of data.

A pilot study was done for Ten percent of a total sample (four nurses ) to check clarity and understanding of the study tool after the necessary modification .This sample excluded from the total sample .

The tools used in this study developed by the researcher based on reviewing the relevant literature.

(Shea et al., 2007)

Content validity; By a jury of 5 Experts in the field of critical care nursing and critical care medicine from South Egypt cancer institute, the tools were tested for content the validity and the necessary modifications.

The content reliability was tested for tool one (knowledge assessment tool and skills assessment tool) by using Cronbach's alpha.

\section{Phase2: Implementation phase}

- Official permission to complete the study was obtained from the head nurses and the hospital nursing director.

- Data was gathered at south Egypt cancer institute in the critical care unit
- At an introductory interview; the researchers introduce themselves to initiate communication.

- Interviewing questionnaire: Filled during the interviewing of every nurse, the aim of the study was explained to each nurse to answer the questions using tool one $\left(1^{\text {st }}\right.$ and $2^{\text {nd }}$ parts $)$

- An observational checklist was carried out to observe and assess the nurses during their work in the morning and afternoon shift and carried without the nurse's attention by using tool two to assess the level of performance during nurse's procedure.

- The data collection was carried out from (January 2018 until May 2018).

- Oral permission for voluntary participation was obtained from nurses.

- The purpose, steps, and benefits of the study were explained to nurses.

- Confidentiality and anonymity of data were ensured.

- The knowledge of each nurse involved in the study was assessed by a questionnaire sheet through a semi-structured interview. An individual interview will be used to collect data, the time needed to complete the tool was 15 minutes.

- The observation checklist was carried out by the researcher while the nurses were on duty in the morning three times during the shift.

- The Observation checklist for nurses carried out during the morning and afternoon shift.

\section{The evaluation phase}

The nurses were assessed during their work in the morning and afternoon shift to assess the level of performance of carotid artery rupture related procedure by using tool one and two. The scoring system for the observational checklist and determine a score for assessment of the nurse 'knowledge classified as Satisfactory $\geq 70 \%$, Unsatisfactory < $70 \%$. Where practice classified as good practice $\geq 70 \%$ and poor practice $<70 \%$.

\section{Statistical analysis}

Collected data were analyzed and tabulated. The researcher used an appropriate statistical method and tests for analysis of the result. The Statistical Package for (SPSS) version (23) was used to analyze data. Descriptive statistics were used for the quantitative data in all questionnaire and the demographic data. Descriptive statistics included: frequencies and percentages. Use Pearson chi-square (cross tabs test) between nurses knowledge and socio-demographic data were done, Pearson Correlation (Correlation is significant at the 0.05 level). The level of significance for this study was 
set at $(\mathrm{p} \leq 0.05)$ to detect any indication of

differences found in the data available.

Results

Table (1): Percentage distribution of demographic data among nurses participant $\mathbf{n}=\mathbf{4 0}$.

\begin{tabular}{|l|c|c|}
\hline \multicolumn{1}{|c|}{ Variables } & Number & Percentage \\
\hline Age & & 5.0 \\
\hline$\leq 20$ yrs. & 2 & 70.0 \\
\hline $20-30$ yrs & 28 & 25.0 \\
\hline$\geq 30$ yrs & 10 & \\
\hline Means \pm SD & & \\
\hline Sex & 17 & 42.5 \\
\hline Male & 23 & 57.5 \\
\hline Female & & \\
\hline Marital status & 15 & 37.5 \\
\hline Single & 21 & 52.5 \\
\hline Married & 3 & 7.5 \\
\hline Divorce & 1 & 2.5 \\
\hline Widowed & & \\
\hline Level of education & 9 & 22.5 \\
\hline Diploma & 1 & 2.5 \\
\hline special diploma & 21 & 52.5 \\
\hline Institute & 9 & 22.5 \\
\hline Bachelor of Nursing & & \\
\hline Years of experience in ICU & 11 & 27.5 \\
\hline$<5$ yrs & 18 & 45.0 \\
\hline $5-10$ yrs & 11 & 27.5 \\
\hline$>10$ yrs & $8.60 \pm 6.02$ & \\
\hline Means \pm SD & & \\
\hline Years of works in hospital & 18 & 45.0 \\
\hline $1<5$ yrs & 6 & 40.0 \\
\hline $5-10$ yrs & 16 & \\
\hline$>10$ yrs & $8.15 \pm 7.07$ & \\
\hline Means \pm SD & & \\
\hline
\end{tabular}

Table (2) Percentage distribution of total scores of nursing knowledge regarding immediate management of carotid artery rupture $(n=40)$.

\begin{tabular}{|c|c|c|}
\hline Score of knowledge & No. & \% \\
\hline Satisfactory $\geq 70 \%$ & 8 & 20.0 \\
\hline Unsatisfactory $\leq 70 \%$ & 32 & 80.0 \\
\hline Total & 40 & 100.0 \\
\hline
\end{tabular}


Table (3): Relation between nurses knowledge and demographic data regarding immediate management of carotid artery rupture among nurses $n=40$.

\begin{tabular}{|c|c|c|c|c|c|c|c|}
\hline \multirow{3}{*}{ Variables } & \multicolumn{4}{|c|}{ Level of knowledge } & & & \multirow{3}{*}{ p.v } \\
\hline & \multicolumn{2}{|c|}{$\begin{array}{l}\text { Satisfactory } \\
\geq 70 \%\end{array}$} & \multicolumn{2}{|c|}{$\begin{array}{c}\text { Unsatisfactory } \\
<70\end{array}$} & \multicolumn{2}{|c|}{ Total } & \\
\hline & $\mathrm{N}$ & $\%$ & $\mathrm{~N}$ & $\%$ & $\mathrm{~N}$ & $\%$ & \\
\hline \multicolumn{8}{|l|}{ Age } \\
\hline$\leq 20$ yrs & 0 & 0.0 & 2 & 5.0 & 2 & 5.0 & \multirow{3}{*}{$\begin{array}{l}0.76 \\
\mathrm{Ns}\end{array}$} \\
\hline 20-30yrs & 6 & 15.0 & 22 & $55.0 \%$ & 28 & 70.0 & \\
\hline$\geq 30 \mathrm{yrs}$ & 2 & 5.0 & 8 & 10.0 & 10 & 25.0 & \\
\hline \multicolumn{8}{|l|}{ Sex } \\
\hline Male & 4 & 10.0 & 13 & 32.5 & 17 & 42.5 & \multirow{2}{*}{$\begin{array}{c}0.46 \\
\mathrm{Ns}\end{array}$} \\
\hline Female & 4 & 10.0 & 19 & 47.5 & 23 & 57.5 & \\
\hline \multicolumn{8}{|l|}{ Marital status } \\
\hline Single & 3 & 7.5 & 12 & 30.0 & 15 & 37.5 & \multirow{4}{*}{$\begin{array}{c}0.755 \\
\mathrm{Ns}\end{array}$} \\
\hline Married & 5 & 12.5 & 16 & 40.0 & 21 & 52.5 & \\
\hline Divorce & 0 & 0.0 & 3 & 7.5 & 3 & 7.5 & \\
\hline Widow & 0 & 0.0 & 1 & 2.5 & 1 & 2.5 & \\
\hline \multicolumn{8}{|l|}{ Level of education } \\
\hline Diploma & 2 & 5.0 & 7 & 17.5 & 9 & 22.5 & \multirow{4}{*}{$\begin{array}{c}0.822 \\
\mathrm{Ns}\end{array}$} \\
\hline special diploma & 0 & 0.0 & 1 & 2.5 & 1 & 2.5 & \\
\hline Institute & 5 & 12.5 & 16 & 40.0 & 21 & 52.5 & \\
\hline Bachelor of Nursing & 1 & 2.5 & 8 & 20.0 & 9 & 22.5 & \\
\hline \multicolumn{8}{|l|}{ Years of experience } \\
\hline $1<5 \quad$ yrs & 3 & 7.5 & 8 & 20.0 & 11 & 27.5 & \multirow{3}{*}{$\begin{array}{c}0.77 \\
\mathrm{Ns}\end{array}$} \\
\hline $5-10$ yrs & 3 & 7.5 & 15 & 37.5 & 18 & 45.0 & \\
\hline$>10$ yrs & 2 & 5.0 & 9 & 22.5 & 11 & 27.5 & \\
\hline \multicolumn{8}{|l|}{ Years of works } \\
\hline $1<5$ yrs & 4 & 10.0 & 14 & 35.0 & 18 & 45.0 & \multirow{3}{*}{$\begin{array}{c}0.94 \\
\mathrm{Ns}\end{array}$} \\
\hline $5-10$ yrs & 1 & 2.5 & 5 & 12.5 & 6 & 15.0 & \\
\hline$>10 \quad$ yrs & 3 & 7.5 & 13 & 32.5 & 16 & 40.0 & \\
\hline
\end{tabular}

Table (4): Percentage distribution of total nursing practice regarding immediate management of carotid artery rupture $(n=40)$.

\begin{tabular}{|l|c|c|}
\hline \multicolumn{1}{|c|}{ Variables } & \multicolumn{2}{c|}{ Total Observation checklist } \\
\cline { 2 - 3 } & $\mathrm{N}$ & $\boldsymbol{\%}$ \\
\hline Good practice $\geq 70 \%$ & 24 & $\mathbf{6 0 . 0}$ \\
\hline Poor practice $<70 \%$ & 16 & $\mathbf{4 0 . 0}$ \\
\hline
\end{tabular}

Table (5): Correlation between Total practice and total knowledge.

\begin{tabular}{|l|c|c|c|}
\hline & Mean & Pearson Correlation & p. v \\
\hline Total practice & $267.600 \pm 12.55$ & .973 & $.001 * *$ \\
\hline Total knowledge & $18.850 \pm 3.27$ & & \\
\hline
\end{tabular}


Table (6): Relation between demographic data and total practice regarding immediate management of carotid artery rupture $(n=40)$.

\begin{tabular}{|c|c|c|c|}
\hline & Variables & Mean \pm SD & p.value \\
\hline \multirow[t]{4}{*}{ Age } & $\leq 20$ yrs & $261.500 \pm 10.606$ & \multirow{4}{*}{.511} \\
\hline & 20-30yrs & $269.071 \pm 12.436$ & \\
\hline & $\geq 30$ yrs & $264.700 \pm 13.507$ & \\
\hline & Total & $267.600 \pm 12.557$ & \\
\hline \multirow[t]{5}{*}{ Level of education } & Diploma & $261.55 \pm 13.286$ & \multirow[t]{5}{*}{.308} \\
\hline & special diploma & $260.00 \pm$ & \\
\hline & Institute & $268.71 \pm 11.309$ & \\
\hline & Bachelor of Nursing & $271.88 \pm 14.146$ & \\
\hline & Total & $267.60 \pm 12.557$ & \\
\hline \multirow{4}{*}{$\begin{array}{l}\text { Years of experience in } \\
\text { ICU }\end{array}$} & $1<5 \mathrm{yrs}$ & $272.72 \pm 9.25$ & \multirow{4}{*}{.247} \\
\hline & $5-10$ yrs & $266.561 \pm 13.69$ & \\
\hline & $>10 \mathrm{yrs}$ & $264.00 \pm 12.87$ & \\
\hline & Total & $267.600 \pm 12.55$ & \\
\hline \multirow[t]{4}{*}{ Years of works in works } & $1<5$ yrs & $270.77 \pm 9.28$ & \multirow[t]{4}{*}{.329} \\
\hline & $5-10$ yrs & $263.16 \pm 16.77$ & \\
\hline & $>10 \mathrm{yrs}$ & $265.68 \pm 13.94$ & \\
\hline & Total & $267.60 \pm 12.55$ & \\
\hline
\end{tabular}

Table (1): Shows that, the majority of nurses $70 \%$ their age ranged from $20-<30$ years old with a mean age of $26.82 \pm 5.35$ and $(25 \%)$ were at the age group of $>30$ years and only $(5 \%)$ of studied nurses age ranged had $<20$ years.57.5\% of them were females, As regarding marital status $(52.5 \%)$ of them were married. As regarding (52.5\%) were having a nursing institute. the majority of nurses $72 \%$ having experience in ICU with a mean age of $8.60 \pm 6.028$ were at the age group of. As regard years of work in a hospital $(55 \%)$ had more than 5 years of work. All of the nurses had not attended any previous training courses about carotid artery rupture.

Table (2): The majority of samples $(80 \%)$ of studied nurses were having unsatisfactory $\leq 70 \%$ : Level of knowledge regarding carotid artery rupture.

Table (3): shows that there was no statistically significant difference between nurse's knowledge and demographic data of studied nurses.

Table (4): The majority of samples $(60 \%)$ of studied nurses were having Good practice $\geq 70 \%$ Level of practice regarding carotid artery rupture.

Table (5): Showed the correlation between Total practice and total knowledge demonstrated with statistical significant difference p.value (.001) .

Table (6): Show the relation between total practice and demographic data clarify that there was no statistically significant difference between demographic data and total practice .

\section{Discussion:}

Carotid blowout syndrome is a hazardous medical crisis commonly coming from entanglements of medications for head and neck malignant growth. A patient without an earlier history of head or neck malignancy introduced to the emergency department with a painless, enlarging neck mass was reported in this study. The mass advanced to acute airway obstruction during imaging of the lesion and required emergency cricothyrotomy to protect the airway. The patient suffered four endovascular treatments to accomplish frequent bleeding thus producing the neurological complication of right middle cerebral artery infarction. (Wang et al., 2015)

Carotid blowout syndrome (CBS) is uncommon and not regularly found in the emergency department (ED). In any case, when it displays, an incite acknowledgment is vital for the patient's survival. CBS or break of the carotid artery was described in 1962 by Borsany and further defined as either an acute hemorrhage or exposure of any portion of the carotid artery. This syndrome occurs in 3\%-4\% of all head and neck cancer (HNC) patients, and it has been assessed already that there are $40 \%$ mortality and sixty percent crushing neurologic horribleness related with carotid artery rupture. (Suárez et al., 2018).

Surgical management of carotid artery rupture is usually technically difficult because the investigation and restoration of the earlier irradiated field are difficult. Endovascular therapy with either lasting balloon occlusion or stent deployment is reportedly a moral different from surgery (Naylor\& van, 2016).

Nursing intervention is centered around prevention of carotid artery rupture a dry, edematous, infected wound to prevent this from stirring the critical care nurse to complete meticulous dressing changes, 
Prevention incorporates enhancing the dietary status, counteracting disease and clogging, advancing recuperating and utilizing safe suctioning if the carotid artery rupture happened. ( Durak, 2014)

The present study revealed that regarding the demographic data; the total number of them were (forty) from different intensive care unit and departments. The majority of nurses' age ranged from twenty to thirty years old, females, married and were nursing institute graduates.

In a similar line Yoshida et al., (2008) with the present investigation discoveries that of the example were hitched, female, their age extended from twenty to twenty-nine years, have a diploma qualification, years of experiences in oncology units under 20 and have in-service training courses related to chemotherapy safety measures.

As well, Abd-Al-Mageed, (2011); conducted a study in the oncology unit at Assiut University Hospital, He discovered that the majority of nurses their ages ranged from twenty to forty years, married, female, and have diploma of nursing, more than half of them their experience exceeded five years.

For the most part, the aggregate scores of nurses' knowledge regarding carotid artery rupture show that (eighty present) of studied nurses were having unsatisfactory less than seventy percent: Level of knowledge which could be reflecting the lack in their scientific preparation. Frawley \& Begley, (2013) were in a similar line who referenced and focused on the nurses needed to be aware of 'at risk' patients, and the warning signs.

From the present study results displayed that none statistically significant difference was found between nurses' knowledge and demographic data of the studied nurses (age, their years of experience in ICU and work in a hospital). In inverse line in a study was conducted in the South Egypt Cancer Institute at Assuit University by Mohamed, (2015) who discovered a statistically significant relation between nurses' knowledge scores with their experience duration.

The finding of the present study demonstrated a relation between total practice and demographic data confirmation that no statistically significant difference was detected of the total checklist and demographic data.

It was observed that notwithstanding the reality with respect to the total practice and total knowledge. It presented that no statistically significant difference was established. The general finding of the study signposted that the participants have poor knowledge and practice. This finding is important for nursing care to head and neck cancer patient because if oncology nurses did not have any development in knowledge and not competent in their skills will be considered as dangerous for giving care to carotid artery rupture and chances for errors can be high as different studies in the past already underlined these focuses (Streiner et al., 2015)

This implies young nurses might have a good willingness for learning and enthusiastic new things as well as their awareness about the continuing education is higher than those who were old age. This result decides with that of Pasila et al., (2017) who described a statistically significant correlation between nurse's performance scores and their duration of the experience.

Finally, carotid artery rupture exceptionally in head and neck cancer patient it is very essential to inaugurate guidelines which encapsulate and evaluate available evidence with the aim of supporting health professionals in choosing the greatest management strategies for an individual patient with a given condition .

Guidelines and their commendations should simplify decision making of health professionals in their daily practice. However, the final decisions concerning an individual patient must be made by the accountable health professional(s) especially the nurse in sounding with the patient and caregiver as appropriate. (Aboyans et al., 2017).

\section{Conclusion}

The total scores of nurses' knowledge regarding carotid artery rupture show that the majority of studied nurses were having an unsatisfactory level of knowledge and good practice level regarding carotid artery rupture

\section{Recommendations}

Continued nursing education and in-service training programs at critical care units should be organized within south Egypt cancer institute and equipped with the necessary educational facilities and materials necessary to upgrade the knowledge and skills of practicing nurses.

\section{References}

1. Abd-Al-Mageed, A., (2011): Nursing care standards for cancer patient Undergoing chemotherapy at Assiut University Hospital. Submitted for Partial Fulfillment of the Requirement of the Doctorate Degree in Medical-Surgical Nursing, faculty of nursing Assiut University, discussion part, pp.112-115.

2. Aboyans, V., Ricco, J., Bartelink, M., Björck, M., Brodmann, M., Cohnert, T., \& EspinolaKlein, C., (2017): ESC Guidelines on the Diagnosis and Treatment of Peripheral Arterial Diseases, 39(9), 763-816. 
3. Bond, K., Brinjikji, W., Murad, M., Cloft, H., \& Lanzino, G., (2017): Endovascular treatment of carotid blowout syndrome. Journal of vascular surgery, 65(3), 883-888.

4. Delucia, P., Ott, T.., \& Palmieri, P., (2009): Performance in nursing. Reviews of human factors and ergonomics, 5(1), 1-40.

5. Durak, M., (2014): Factors affecting the companies' preferences on integrated reporting. International Journal of Contemporary Economics and Administrative Sciences, 3(3-4), 68-85.

6. Frawley T., \& Begley C., (2013): Causes and prevention of carotid artery rupture, British Journal of Nursing, List of Issues, Volume 14, Issue 22, P.P334

7. Hofmann, V., Ukkat, J., \& Pudszuhn, A., (2012): Perforation of a carotid artery causing a cervical hematoma. HNO, 60(7), 663-666.

8. Mohamed, N., (2015): Effect of Designed Nursing Protocol on Nurse's knowledge And Practice Regarding Chemotherapy. Med. J. Cairo. Univ, 83(2), 209-216

9. Naylor, A., \& van den Berg, J., (2016). Technical aspects of carotid revascularization. Oxford Textbook of Vascular Surgery, 416.

10. Pasila, K., Elo, S., \& Kääriäinen, M., (2017): Newly graduated nurses' orientation experiences: A systematic review of qualitative studies. International journal of nursing studies, 71, 17-27.

11. Riesenberg, L., Leisch, J., \& Cunningham, J., (2010): Nursing handoffs: a systematic review of the literature. AJN The American Journal of Nursing, 110(4), 24-34.

12. Shah, H., Gemmete, J., Chaudhary, N., Pandey, A., \& Ansari, S., (2011): Acute lifethreatening hemorrhage in patients with head and neck cancer presenting with carotid blowout syndrome: follow-up results after initial hemostasis with covered-stent placement. American Journal of Neuroradiology, 32(4), 743-747.

13. Shea, B., Grimshaw, J., Wells, G., Boers, M., Andersson, N., Hamel, C., \& Bouter, L., (2007): Development of AMSTAR: a measurement tool to assess the methodological quality of systematic reviews. BMC medical research methodology, 7(1), 10.

14. South Egypt cancer institute statistical record, (2017).

15. Streiner, D., Norman, G., \& Cairney, J., (2015): Health measurement scales: a practical guide to their development and use., 5th ed Oxford University Press, USA., P.P.399

16. Suárez, C., Fernández-Alvarez, V., Hamoir, M., Mendenhall, W., Strojan, P., Quer, M., \& Ferlito, A., (2018): Carotid blowout syndrome: modern trends in management. Cancer management and research, 10, 5617.

17. Wan, W., Lai, V., Lau, H., Wong, Y., Poon, W., \& Tan, C., (2013): Endovascular treatment paradigm of carotid blowout syndrome: a review of 8-years' experience. European journal of radiology, 82(1), 95-99.

18. Wang, C., Wang, C., Jiang, R., Lin, J., \& Liu, S., (2015): Carotid blowout in patients with head and neck cancer: associated factors and treatment outcomes. Head \& neck, 37(2), 265272.

19. Yoshida J., Kosaka H., Nishida S., \& Kumagai S., (2008): Actual conditions of the mixing of antineoplastic drugs for injection in hospitals in Osaka Prefecture, Japan., Journal of Occupational Health, 50 (1): 86-91. 10.1539/ joh.50.86. 